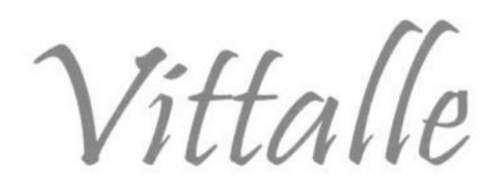

\title{
Projeto escola do trabalhador: perfil do agente comunitário de saúde
}

\author{
Thereza Cristina de Souza Mareco ${ }^{\mathrm{a}^{*}}$, Fátima Sonally Sousa Gondim ${ }^{\mathrm{b}}$, Aurélio Matos \\ Andrade $^{c}$, Ione Silva Barros ${ }^{\mathrm{d}}$, Therese Hofmann Gatti Rodrigues da Costa ${ }^{\mathrm{e}}$

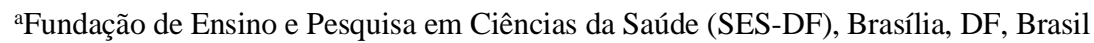 \\ becretaria de Vigilância em Saúde do Ministério da Saúde - SVS/MS, Brasil \\ 'Fundação Oswaldo Cruz- Fiocruz Brasília, Brasília, DF, Brasil \\ dinstituto Federal de Educação, Ciência e Tecnologia de Goiás (IFG), Águas Lindas de Goiás, GO, Brasil \\ ${ }^{\mathrm{e}}$ Universidade de Brasília, Brasília, DF, Brasil
}

Histórico do Artigo
Recebido em:
09/01/2020
Aceito em:
16/04/2020
Palavras-chave:
Curso EaD; ACS;
qualificação; MOOC

Histórico do Artigo

Palavras-chave:

Curso EaD; ACS; qualificação, MOOC

\begin{abstract}
RESUMO
A modalidade de ensino a distância tem sido requisitada por representar uma possibilidade de educação com vistas a superar a carência de formação em diversas áreas de conhecimento e por favorecer o acesso nas regiões longínquas. Este estudo identificou os aspectos relativos ao perfil sociodemográfico dos alunos e descreveu os conteúdos educacionais adotados no decorrer do curso "o perfil e a função dos Agentes Comunitários de Saúde (ACS)". Foi realizado um estudo de métodos mistos (quantitativo transversal descritivo e qualitativo descritivo). Há maior participação dos cursistas são do sexo feminino e da população jovem, na idade entre 18 e 24 anos e 25 e 34 anos. Desses 45,19\% possuem ensino médio completo e apenas 5,10\%, o bacharelado. Considerando o contexto atual do País, onde ainda há um elevado número de pessoas desempregadas, torna-se necessário um maior investimento no combate ao desemprego e na qualificação dos trabalhadores, bem como nas pesquisas relacionadas a estas temáticas.
\end{abstract}

Worker's school project: profile of the community health agent

Keywords: Distance Education course; ACS; qualification; MOOC

\section{ABSTRACT}

The distance learning modality has been requested because it represents a possibility of education in order to overcome the lack of training in several areas of knowledge and to favor the access in the distant regions. This study identified the aspects related to the students' sociodemographic profile and described the educational content adopted during the course "the profile and function of Community Health Agents (CHA)". It was conducted a study of mixed methods (descriptive transversal quantitative and descriptive qualitative). There is a greater participation of female students and young people, aged between 18 and 24 years and 25 and 34 years. Of these $45.19 \%$ have completed high school and only $5.10 \%$ have a bachelor's degree. Considering the current context of the country, where there are still a high number of unemployed people, it is necessary to invest more in combating unemployment and in the qualification of workers, as well as in research related to these themes.

\section{Introdução}

A Escola do Trabalhador (ET) é uma das ações implementadas pelo então Ministério do Trabalho, hoje Ministério da Economia, que tem a função de qualificar trabalhadores brasileiros. A ET tem ofertado cursos na modalidade à distância $(\mathrm{EaD})$ em doze eixos temáticos estabelecidos com base no Guia de Cursos de Formação Inicial e Continuada do Ministério da Educação, respeitando as definições da Classificação Brasileira de Ocupações: informática e comunicação; ambiente e saúde; turismo, hospitalidade e lazer; recursos naturais; desenvolvimento educacional e social; produção alimentícia; controle e processos industriais; infraestrutura; gestão e negócios; produção industrial; produção cultural e design; e segurança (1).

A expansão dos cursos na modalidade $\mathrm{EaD}$ foi impulsionada a partir do fim da década

\footnotetext{
* Autor correspondente: thereza.csm@ hotmail.com (Mareco T.C.S.)
} 
de 80, como consequência da informatização e do surgimento de novas tecnologias. Essa modalidade de ensino tem sido muito requisitada por representar uma possibilidade de educação com vistas a superar a carência de formação em diversas áreas de conhecimento e por favorecer o acesso nas regiões longínquas. De acordo com Marin et al. (2), a EaD é uma modalidade de ensino que utiliza processos de mediação tecnológica cujas potencialidades podem surpreender positivamente aos estudantes e professores envolvidos, uma vez que as atividades de ensino e aprendizagem são realizadas por meio de estratégias pedagógicas que valorizam os sujeitos, a intersubjetividade e a aprendizagem colaborativa, desenvolvendo a autonomia e estimulando a interatividade.

A profissão do Agente Comunitário de Saúde (ACS) caracteriza-se pelo exercício de atividade que visa promover a saúde da população, mediante ações domiciliares comunitárias, individuais ou coletivas, desenvolvidas no Sistema Único de Saúde (SUS) e sob supervisão do gestor local, através da Secretaria Municipal de Saúde. Nesse sentido, o Projeto de Lei $n^{\circ}$ 6.437/2016 pretende fortalecer os direitos e as atribuições para o exercício do cargo de ACS e menciona sobre o cumprimento de determinados requisitos, como ter concluído o ensino médio e ter realizado um curso de formação inicial de 40 horas (3).

Observando essas obrigatoriedades, o curso "o perfil e a função dos Agentes Comunitários de Saúde (ACS)" presente no eixo "ambiente e saúde" tem a perspectiva de preparar, qualificar e oportunizar pessoas para atuar como ACS, objetivando fomentar o mercado de trabalho e reduzir o desemprego, bem como desenvolver ações de promoção à saúde e prevenção de doenças e agravos.

Dessa forma, este artigo identificou os aspectos relativos ao perfil sociodemográfico dos alunos e descreveu os conteúdos educacionais adotados no decorrer do curso "o perfil e a função dos Agentes Comunitários de Saúde (ACS)".

\section{Método}

O antigo Ministério do Trabalho, hoje Ministério da Economia, com a coparticipação da Universidade de Brasília (UnB) realizou o curso "o perfil e a função dos Agentes Comunitários de Saúde (ACS)”, para formação de profissionais de saúde, com foco nos ACS.

O presente trabalho foi realizado por meio de estudo métodos mistos, quantitativo com abordagem transversal descritiva no qual identificou os aspectos relativos ao perfil sociodemográfico dos alunos; e qualitativo descritivo em relação aos conteúdos educacionais adotados no decorrer do curso "o perfil e a função dos Agentes Comunitários de Saúde (ACS)" (4).

A coleta de dados foi realizada por questionário estruturado e avaliativo aplicado ao final do curso. A análise de dados foi organizada pelo software Microsoft Excel 2016 para os dados quantitativos e pelo software Nvivo para categorizar os dados qualitativos.

As matrículas alcançaram uma amostragem de 2.981 cursistas. Vale ressaltar que os alunos que obtiveram nota igual ou superior a cinco receberam o certificado de conclusão de curso pela UnB.

O curso foi dividido em três eixos: 1) perfil das competências profissionais do ACS; 2) processo de trabalho do ACS e da equipe; e 3) humanização do cuidado da Estratégia Saúde da Família (ESF).

O perfil sociodemográfico dos alunos do curso foi investigado por meio das variáveis dispostas acerca do sexo, idade, escolaridade e naturalidade. Acerca dos conteúdos 
foram abordadas: Tema 1, as competências do profissional: Agente Comunitário de Saúde (ACS); Tema 2, atividades laborais individuais e coletiva do ACS; e Tema 3, o atendimento, direitos e valorização no ambiente de trabalho que foram categorizados pelo método de análise de conteúdo de Bardin (5).

Os procedimentos deste estudo atenderam ao Parágrafo Único do art. $1^{\circ}$ da Resolução $\mathrm{n}^{\mathrm{o}} 510$, de 07 de abril de 2016, que dispõe sobre as pesquisas que utilizam informações de domínio público prescindem registro e avaliação pelo sistema do Comitê de Ética e Pesquisa e da Comissão Nacional de Ética em Pesquisa -Resolução nº 510, 2016 (6).

\section{Resultados e discussão}

\section{Dados Sociodemográficos}

No que diz respeito à distribuição de gênero dos alunos do curso "o perfil e a função dos Agentes Comunitários de Saúde (ACS)”, 73\% são do gênero feminino, corroborando com Almeida (7), os paradigmas que rodeiam o papel da mulher na sociedade vem sendo desmistificado, dessa forma a mulher contemporânea tem atribuições acadêmicas, como foi possível constatar no estudo do IBGE, que a participação da mulher é maior na busca de conhecimento e qualificação profissional para ingressar no mercado de trabalho (8) (Quadro 1).

Quadro 1 - Dados sociodemográficos dos alunos que realizaram o curso "O perfil e a função dos Agentes Comunitários de Saúde (ACS)", Brasil, 2017.

\begin{tabular}{|l|l|l|}
\hline VARIÁVEIS & N & \% \\
\hline Sexo & 2184 & $73 \%$ \\
\hline Feminino & 797 & $27 \%$ \\
\hline Masculino & & \\
\hline Idade & 118 & $4,01 \%$ \\
\hline Menores de 18 anos & 911 & $30,92 \%$ \\
\hline $18-24$ & 897 & $30,45 \%$ \\
\hline $25-34$ & 641 & $21,76 \%$ \\
\hline $35-44$ & 274 & $9,30 \%$ \\
\hline $45-54$ & 103 & $3,50 \%$ \\
\hline $55-64$ & 2 & $0,07 \%$ \\
\hline Maiores de 65 & & \\
\hline Escolaridade & 13 & $0,44 \%$ \\
\hline Mestrado & 69 & $2,31 \%$ \\
\hline Especialização & 500 & $10.94 \%$ \\
\hline Ensino Superior & 524 & $17,58 \%$ \\
\hline Ensino superior incompleto & 1347 & $45,19 \%$ \\
\hline Ensino médio completo & 313 & $10,50 \%$ \\
\hline Ensino médio incompleto & 177 & $5,94 \%$ \\
\hline Ensino técnico completo & 97 & $3,25 \%$ \\
\hline Ensino fundamental completo & 79 & $2,65 \%$ \\
\hline Ensino fundamental incompleto & 36 & $1,21 \%$ \\
\hline Não responderam & & \\
\hline Naturalidade (UF) & 444 & $15,51 \%$ \\
\hline São Paulo & 296 & $10,34 \%$ \\
\hline Minas Gerais & 285 & $9,96 \%$ \\
\hline Distrito Federal & 272 & $9,50 \%$ \\
\hline Rio de Janeiro & 192 & $6,71 \%$ \\
\hline Ceará & 1373 & $47,97 \%$ \\
\hline Demais localidades & & \\
\hline & & \\
\hline
\end{tabular}

Fonte: Ministério do Trabalho (2018). 
A faixa etária majoritária dos cursistas foi entre 18 a 34 anos $(61,37 \%)$ e em relação ao nível de escolaridade em torno $76 \%$ da amostragem possuem ensino médio completo. Em comparação com a Síntese de Indicadores Sociais (SI) do IBGE, nota-se que o número de pessoas jovens sem estudar e sem trabalhar atingiu 25,8\% da população brasileira na faixa etária de 16 a 29 anos (9). Contudo, em 2012 aconteceu uma redução para $22,8 \%$ dos jovens na mesma faixa etária que estavam nessa mesma condição. Tendo isso em vista, infere-se que é crescente o número de jovens nessa faixa etária que possam estar buscando qualificações e capacitações para retornar ao mercado de trabalho (Quadro 1).

No tocante a naturalidade, $(15,51 \%)$ pertenciam ao estado de São Paulo, seguido de Minas Gerais (10,34\%), Rio de Janeiro $(9,5 \%)$ e Ceará $(6,71 \%)$. Vale salientar que $47,97 \%$ se referem a demais localidades, as quais não tivemos acesso no momento da coleta dos dados.

Referente ao vínculo empregatício 69\% dos alunos estão desempregados. Dentre esses a maioria da amostra (656) está sem trabalho há mais de 24 meses (Figura 1).

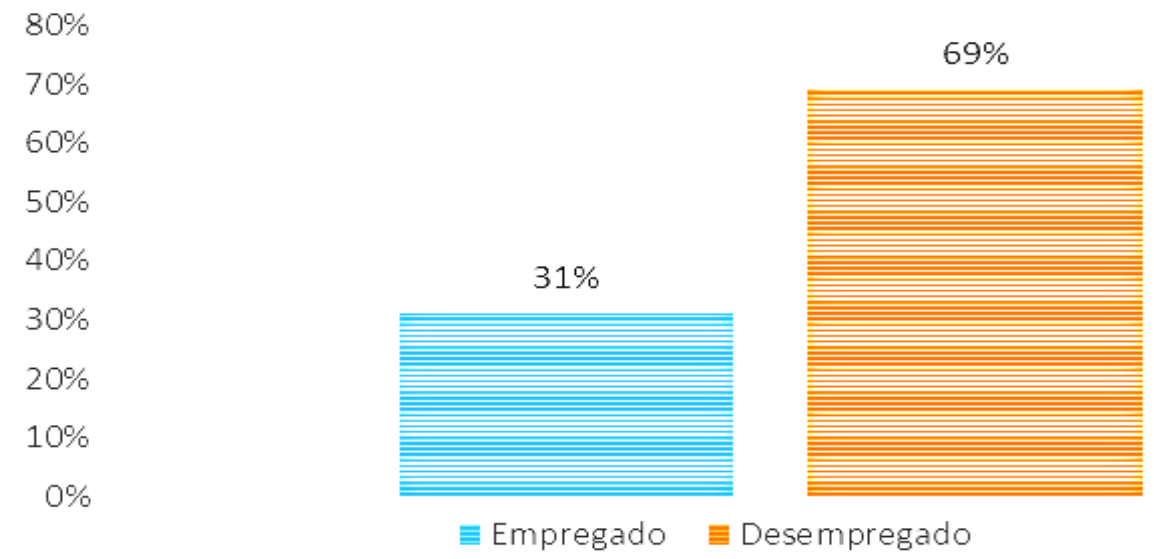

Figura 1 - Distribuição dos alunos em relação à situação empregatícia, Brasil, 2017. Fonte: BRASIL, 2019e adaptado pelos autores.

Destarte, no Brasil o número de jovens entre 18 e 24 anos de idade com 11 anos de estudo ou mais ainda é baixo, apenas 36,8\% dos jovens foram contemplados em 2008. Cabe salientar que a raça ou a cor e as desigualdades regionais favorecerem as pessoas brancas entre 18 e 24 anos (40,7\%), quando comparadas aos jovens pretos e pardos com 11 anos ou mais de estudos $(33,3 \%)$. No que tange às macrorregiões brasileiras, a Sudeste tem um total de $43,8 \%$ de jovens com 11 anos ou mais de estudos, enquanto que a região Nordeste possui $29,2 \%$ dos jovens nessa mesma condição (10).

Vale salientar que a proporção de pessoas com 16 anos de idade ou mais que ocupavam trabalhos formais, em 2014 , era de $57,7 \%$ da população, sendo desse percentual 58,6\% homens e 56,5\%, mulheres $(10,11)$. Portanto, o mercado de trabalho tem se tornado cada vez mais competitivo, exigindo melhor qualificação e capacitação profissionais. De acordo com Proni (12), as mulheres estão em desvantagem, o que pode ser um fator determinante para que a busca por um curso seja maior no sexo feminino.

Diante dessa realizada, o governo brasileiro busca oferecer aos jovens programas de qualificação profissional e esportiva, a fim de melhorar os indicadores do país e fortalecer o crescimento empregatício (13).

Conteúdos abordados no curso 
No que concerne ao conteúdo abordado no curso, no Tema 1 foi elencado o perfil das competências profissionais do ACS. Para isso, foi necessário apresentar melhor o conceito de ACS, a profissão, a formação e as competências profissionais necessárias para esta formação.

O ACS é um profissional que compõe a equipe multiprofissional nos serviços de atenção básica à saúde. Suas atividades transcendem o campo da saúde na medida em que requerem atenção a múltiplos aspectos das condições de vida da população. Estas características constituem atributos de generalidade deste profissional e o situa como categoria muito particular, não comparável ou agrupável com outras historicamente existentes no campo da saúde. Ainda, é um personagem fundamental, pois é quem está mais próximo dos problemas que afetam a comunidade, é alguém que se destaca pela capacidade de se comunicar com as pessoas e pela liderança natural que exerce (14).

Relacionado às suas competências profissionais, o ACS realiza atividades de prevenção de doenças e promoção da saúde, por meio de ações educativas em saúde realizada em domicílios ou junto às coletividades, em conformidade com os princípios e diretrizes do SUS e estende, também, o acesso da população às ações e aos serviços de informação, de saúde, de promoção social e de proteção da cidadania (15).

O trabalho do ACS é considerado uma extensão dos serviços de saúde dentro do seu território, pois ele representa um elo entre a comunidade e o serviço de saúde. De acordo com a Lei $n^{\circ}$ 10.507, de 10 de julho de 2002, destacam-se entre as ações desenvolvidas pelo ACS: o mapeamento da área de atuação; o cadastro das famílias de sua microárea e sua atualização; a identificação, junto a equipe, das áreas e famílias de risco; a realização, mensalmente, de visitas domiciliares às famílias de sua responsabilidade; a participação no processo educativo junto às famílias; o incentivo à participação comunitária; a discussão com a equipe sobre a realidade da comunidade onde atua e a contribuição para possíveis soluções de problemas; a comunicação à equipe sobre casos de doenças que necessitam de notificação; a participação no grupos educativos; e a verificação da caderneta de vacinação das crianças (16).

As competências explicitam as capacidades às quais se recorre para a realização de determinadas atividades num determinado contexto técnico-profissional e sociocultural. Logo, a competência profissional do ACS inclui capacidades, atividades, contextos e a combinação de conhecimentos, habilidades, experiências e qualidades pessoais usadas efetivamente e apropriadamente em atos individuais e coletivos, como resposta às várias circunstâncias relativas a prática profissional (17).

Entender a competência profissional nestes termos possibilita considerar o trabalhador como capaz de conhecer a utilidade e os impactos das ações que ele realiza, de compreender que os grupos sociais não são abstratos ou distantes, sendo possível conhecer suas necessidades e modos de viver e, sobretudo, de compreender a importância do processo de interação da equipe de trabalho com os indivíduos, os grupos e as coletividades com os quais trabalha (18).

O Tema 2 diz respeito ao processo de trabalho do ACS e sua relação com a equipe. Para isso, instigou os conceitos de processo de trabalho, de equipe de saúde e outros relacionados a estas duas temáticas principais.

$\mathrm{O}$ processo de trabalho designa-se como o modo pelo qual as atividades são desenvolvidas e como a equipe realiza, independente da área de atuação. Assim, podese dizer que o trabalho, em geral, é o conjunto de procedimentos pelos quais os homens atuam, por intermédio dos meios de produção, sobre um objeto. O objetivo do processo de trabalho é a produção de um dado objeto ou condição que determina o produto específico de cada processo de trabalho, tendo por finalidade atingir os objetivos 
propostos pela equipe (18).

É de fundamental importância que os profissionais da ESF desenvolvam habilidades competentes para a aplicação de instrumentos que possibilitem a reflexão do seu processo de trabalho de forma crítica e transformadora. A reflexão do processo de trabalho e a inserção do planejamento da equipe permite muitas vezes suprir as necessidades encontradas e, desse modo, atingir os objetivos propostos, garantindo melhoria na qualidade de vida dos usuários (19).

A equipe de saúde é formada por pessoas com histórias, formações, práticas e saberes diferentes. É um conjugado de pessoas que se encontram para produzir e reproduzir o cuidado de uma população. Na equipe de saúde existem sempre movimentos permanentes de articulação/desarticulação, crença/descrença no trabalho, ânimo/desânimo, invenção/resistência à mudança, pois toda equipe está em constante processo de mudança. E cada profissional deve estar atento ao processo de mudança de aprendizagem (20).

O trabalho na área da saúde é uma atuação composta por diferentes atores que se encontram envolvidos e destinados à produção do cuidado à saúde da população. $\mathrm{O}$ conjunto de trabalhadores que compõem uma unidade de saúde possui uma heterogeneidade, em que cada trabalhador atua em um determinado lugar, tem responsabilidades específicas e produz ações para que determinado objetivo antes estabelecido seja alcançado (14).

Para realização de um atendimento qualificado, torna-se necessário que a população sob responsabilidade da equipe esteja cadastrada e seja acompanhada, bem como ocorra a compreensão de suas necessidades de saúde como condições sociais, econômicas e ambientais. A equipe e as famílias devem compartilhar de responsabilidades mútuas pela saúde, visto a importância na adequação das ações de saúde às necessidades da população, estabelecendo ao mesmo tempo uma forma de controle social e participação popular (15).

Ainda é preciso que a equipe de saúde trabalhe junto, compartilhando de experiências, conhecendo a realidade da comunidade e realizando ações de acolhimento, atendimento e prestação de serviço de qualidade. O trabalhador precisa executar ao longo de seu serviço etapas próprias de sua função.

Dentre as funções desempenhadas pela equipe de saúde, tem-se: a coleta de informações sobre a comunidade; o diagnóstico de saúde da comunidade; o planejamento das ações; e a execução das ações planejadas. Para a coleta de informações diversos instrumentos podem ser utilizados e cada um possui um objetivo central. Como exemplo, há o cadastro das famílias; o mapeamento da comunidade; a visita domiciliar; e o planejamento da equipe. Todo o método de registro, acompanhamento e planejamento das ações possibilita a efetivação e a consolidação do processo de trabalho do ACS, qualificando sua execução e desenvolvimento (18).

O cadastramento possibilita o real conhecimento das condições de vida das famílias residentes nas áreas de atuação, tais como: composição familiar; existência de população indígena, quilombola e assentada; escolaridade; acesso ao saneamento básico; número de pessoas por sexo e idade; condições de habitação; desemprego; e doenças referidas, entre outras informações (21).

Desse modo, ao realizar o cadastramento e identificar os principais problemas de saúde, o ACS contribui para que os serviços de saúde possam oferecer uma atenção mais integral direcionada à família, de acordo com a realidade e os problemas de cada comunidade. Para total efetivação dessa conduta é preciso que todas as famílias e os usuários estejam cadastrados na unidade, sendo esta uma responsabilidade do ACS. Este cadastro é feito através da visita domiciliar, momento no qual são preenchidas 
todas as informações cadastrais, que devem ser atualizadas mensalmente conforme alterações (22).

O mapeamento, por sua vez, permite identificar os estabelecimentos e as instituições no território, tais como: escola, creches, comércio, praça, igreja, lixo, entre outros. Aborda ainda informações importantes para o diagnóstico de saúde da comunidade, identificando outros locais os quais os moradores costumam frequentar em prol da resolução de problemas de saúde, como rezadores ou casa de benzedeiras (15).

A construção do mapa deve-se dar entre a equipe da ESF e nele deve constar todas as características territoriais, como ruas e localizações, e demais informações pertinentes, como saneamento básico e calçamento, além da localização da própria ESF e da distribuição das áreas por população e suas microáreas por ACS (23).

Por retratar o território onde acontecem mudanças, o mapa deve possuir uma estrutura dinâmica e ser constantemente atualizado. O ACS deve sempre ter a cópia do mapa da microárea para facilitar o acompanhamento das mudanças da comunidade. O mapa deve sempre estar exposto em um lugar visível a todos, se possível for, na recepção da unidade. Trabalhar com mapas é uma forma de retratar e aumentar conhecimentos sobre a comunidade. O mapa deve ser uma ferramenta indispensável, podendo ajudar a organizar melhor o trabalho da equipe (22).

A visita domiciliar é a atividade mais importante do processo de trabalho do ACS. Ao entrar na casa de uma família, o ACS entra não somente no espaço físico, mas em tudo o que esse espaço representa, uma vez que há uma família com seus códigos de sobrevivência, crenças, cultura e uma história.

A sensibilidade/capacidade de compreender o momento certo e a maneira adequada de se aproximar e estabelecer uma relação de confiança é uma das habilidades mais importantes do ACS. Isso ajudará a construir o vínculo necessário ao desenvolvimento das ações de promoção, prevenção, controle, cura e recuperação (19).

Por meio das visitas domiciliares é possível atestar o diagnóstico de saúde construído através da soma de todos os instrumentos de pesquisa utilizados para a coleta de informações. A junção do mapeamento e do cadastramento familiar permite à equipe ter o perfil situacional e sociodemográfico, contribuindo no diagnóstico de saúde da comunidade.

Para a efetivação e a ordenação do processo de trabalho do ACS é preciso executar um planejamento, que não pode ser considerado um método improvisado. O planejamento requer preparo e organização das ações a serem desenvolvidas. Dessa forma, deve-se: acompanhar sua execução; reformular as decisões já tomadas; redirecionar sua execução; e, ao término, avaliar seu resultado. No acompanhamento da execução das ações, é imprescindível verificar se os objetivos pretendidos estão sendo alcançados ou não, para poder intervir a tempo de modificar o resultado final e alcançar, assim, o objetivo almejado (18).

De acordo com o Ministério da Saúde (24), o ACS, de forma sintonizada com a equipe, pode planejar o seu trabalho, dando prioridade às famílias que necessitam ser acompanhadas com maior frequência, como as famílias consideradas de risco e as que pertencem aos grupos prioritários. Esse diagnóstico é um ponto de partida para o ACS e a equipe organizarem o calendário de visitas domiciliares e demais atividades.

No âmbito do planejamento das ações, cabe ao ACS: a) desenvolver ações que busquem a integração entre as equipes de saúde e a população adstrita à ESF, considerando as características e as finalidades do trabalho de acompanhamento de indivíduos e grupos sociais ou coletividades; b) realizar, em conjunto com a equipe, atividades de planejamento e avaliação das ações de saúde no âmbito de adstrição da equipe; c) desenvolver ações de promoção social e de proteção e desenvolvimento da 
cidadania no âmbito social e da saúde; d) planejar junto com a equipe as visitas domiciliares; e) desenvolver, em equipe, ações de promoção da saúde visando a melhoria da qualidade de vida da população, a gestão social das políticas públicas de saúde e o exercício do controle da sociedade sobre o setor da saúde; e f) desenvolver ações de prevenção e monitoramento dirigidas a grupos específicos e a doenças prevalentes, conforme definido no plano de ação da equipe de saúde e nos protocolos de saúde pública.

Sendo assim, o planejamento requer realizar, em conjunto com a equipe, atividades e avaliação das ações de saúde no âmbito da administração da unidade básica de saúde, como também estimular a participação da população no planejamento, no acompanhamento e na avaliação das ações locais de saúde.

O planejamento participativo em saúde, no âmbito da atenção básica no SUS, em especial na ESF, envolve a reflexão e o trabalho coletivo de todos os que atuam neste contexto: trabalhadores de saúde, usuários do sistema e gestores. Planejar coletivamente exige o conhecimento prévio das necessidades de saúde da população e um esforço conjunto para que sejam propostas ações de saúde que respondam efetivamente a essas necessidades. Essa proposta de planejamento é uma estratégia que propõe um novo agir, caracterizado pela participação e interação de muitas pessoas, engajadas politicamente e com interesses e objetivos comuns (25).

No Tema 3 foi discutido sobre o processo de humanização do cuidado na ESF. Neste sentido, foram destacados os aspectos relativos à Política Nacional de Humanização (PNH), como seus princípios e sua relação com a humanização do cuidado.

A PNH, lançada em 2003, busca pôr em prática os princípios do SUS no cotidiano dos serviços de saúde, produzindo mudanças nos modos de cuidar e gerir. A PNH estimula a comunicação entre gestores, trabalhadores e usuários para construir processos coletivos de enfrentamento de relações de poder, trabalho e afeto que, muitas vezes, produzem atitudes e práticas desumanizadoras que inibem a autonomia e a corresponsabilidade dos profissionais de saúde em seu trabalho e dos usuários no cuidado de si (15).

A PNH aposta na inclusão de trabalhadores, usuários e gestores na produção e gestão do cuidado e dos processos de trabalho. A mesma busca a redução das filas e do tempo de espera, com aplicação do acesso; o atendimento acolhedor e resolutivo, baseado em critérios de risco; a implantação de modelo de atenção com responsabilização e vínculo; a garantia dos direitos dos usuários; a valorização do trabalho na saúde; e a gestão participativa dos gestores de saúde (15).

A humanização tem sido abordada constantemente nos atuais debates sobre o contexto de saúde e nas recentes pesquisas da área da saúde como tema relevante e como subsídio para a melhoria do cuidado e para a consolidação dos princípios e valores do SUS, como a valorização dos aspectos emocionais e dos que envolvem mudanças na gestão e nas práticas de saúde; aspectos relacionados ao ser humano como forma de percebê-lo como um ser único e insubstituível, percebendo-o como doente único, que merece ser tratado com respeito, acolhimento, empatia, escuta, diálogo, circunstâncias sociais, éticas, educacionais e psíquicas, além da valorização dos significados atribuídos pelo ser humano à sua experiência de adoecimento e sofrimento, da prevalência da comunicação e do diálogo (22).

A humanização focaliza na relação com os compromissos e direitos humanos; na garantia de acesso aos usuários dos serviços de saúde e na possibilidade de estabelecer vínculos solidários e de participação coletiva na gestão dos serviços de saúde, sendo ainda considerada como o encontro dos sujeitos e suas subjetividades (26).

O termo humanização é aplicado àquelas situações em que, além de valorizar o 
cuidado em suas dimensões técnicas e científicas, se reconhecem os direitos do paciente, autonomia e subjetividade, sem esquecer do reconhecimento do profissional também enquanto ser humano, ou seja, pressupõe uma relação sujeito/sujeito (15).

\section{Considerações finais}

A crise econômica do País também aumentou o número de desempregados no Brasil. Deste modo, a inserção no mercado de trabalho se tornou mais seletiva e competitiva, em que o empregador procura por pessoas mais qualificadas. Assim, os cursos em EAD proporcionam o conhecimento em várias áreas e favorecem o acesso a diversas regiões. Ainda, é importante salientar que esta modalidade de ensino é mais acessível, pois possibilita que cada um estude no seu tempo conciliando as demais atividades ao estudo.

Vale frisar que o curso ofertado possibilitou a qualificação de 2.981 alunos de várias regiões do País e com perfis diferenciados, do ensino fundamental incompleto à pósgraduação (mestrado, por exemplo), o que se torna relevante em relação à amplitude e à abrangência do curso, o que impacta a relevância do Projeto Escola do Trabalhador. Entre os principais resultados, destacam-se a maior prevalência do sexo feminino (73\%), na faixa etária de 18 a 24 anos, com ensino médio completo (45,19\%). Como a maior prevalência de cursistas desempregados (69\%).

A pesquisa torna-se relevante à medida que demonstra que cada vez mais cedo os jovens buscam por novos conhecimentos a fim de se aperfeiçoarem para ingressarem no mercado de trabalho ou se qualificarem para o exercício de suas atividades. Atualmente, é perceptível a participação das mulheres com o mesmo propósito, a qual quebra o paradigma sobre os direitos e deveres do segmento e mostra que o sexo feminino também passou a ter uma dupla jornada de trabalho, destacando-se, em grande número, nas atividades externas, além dos referentes à família e ao lar.

Com a realização do curso de ACS, pré-requisito para o exercício da profissão, segundo a Lei $\mathrm{n}^{\mathrm{0}} 6.437 / 16$, estes profissionais, que se encontram desempregados e que finalizaram o curso, apresentam qualificação e estão aptos a realizarem concursos e/ou processos seletivos, diante da apresentação do certificado de conclusão. Apresentam, ainda, um conhecimento prévio em relação à temática, com base nos temas abordados durante o curso, através dos conteúdos e das metodologias de ensino-aprendizagem. As ideias aqui apresentadas representam um norte para a consolidação do processo de trabalho do Agente Comunitário de Saúde, que perfaz todo um caminho de construção, reconstrução e dinamismo para execução de suas ações (3).

Os ACS devem sempre procurar desenvolver, ao longo de seu trabalho, a compreensão dos sujeitos como atores sociais e suas condições de saúde no processo formativo do cuidado, empoderando os sujeitos e, ao mesmo tempo, responsabilizando-o pela sua concepção de saúde, comunidade e sociedade. Esse processo educacional para os ACS possibilita a construção de práticas diferenciadas de ensino e do saber comunitário, enriquecendo cada vez suas práticas. Além disso, é necessário intervir e investir na formação dos trabalhadores de saúde, considerando que as instituições formadoras, as universidades e a gestão do SUS têm um importante papel nessa direção, pois os modelos ainda existentes de formação, direcionados à atenção primária, são apontados como necessários à reflexão e às mudanças.

Ademais, considerando o contexto atual do País, onde ainda há um elevado número de pessoas desempregadas, torna-se necessário um maior investimento no combate ao desemprego e na qualificação dos trabalhadores, bem como nas pesquisas relacionadas a estas temáticas, tornando assim relevante não apenas os cursos ofertados, mas também, o 
Projeto escola do Trabalhador, que favorece os profissionais que não estão em atuação.

\section{Referências}

1. BRASIL. Ministério do Trabalho. Portal Emprega Brasil. Disponível em: https://empregabrasil.mte.gov.br/551/ministerio-do-trabalho-lanca-escola-do-trabalhador/. Acesso em: 07 de out. 2019.

2. Marin MJS, Nascimento EN, Tonhom SFR, Alves BAD, Girotto MA, Otani MAP, Silva LCP. Formação na Modalidade a Distância pela Universidade Aberta do SUS: Estudo Qualitativo sobre o Impacto do Curso na Prática Profissional. Revista Brasileira de Educação Médica 2017; 41(2): 201-9.

3. BRASIL. Congresso. Câmara dos Deputados. Projeto de lei no 6.437-A, de 2016. Disponível em: http://www.camara.gov.br/sileg/integras/1563131.pdf Acesso em: 07 de out. 2019.

4. Creswell JW, Plano Clark VL. Designing and conducting mixed methods research. 2nd. Los Angeles: SAGE Publications, 2011.

5. Bardin L. Análise de conteúdo. Lisboa: Edições 70; 2016.

6. BRASIL. Ministério da Saúde. Resolução $\mathrm{n}^{\circ}$ 510, de 07 de abril de 2016. Disponível em: http://conselho.saude.gov.br/resolucoes/2016/Reso510.pdf. Acesso em: 07 de out. 2019.

7. Almeida LS. Mãe, cuidadora e trabalhadora: as múltiplas identidades de mães que trabalham. Rev. Dep. Psicol 2007; 19(2): 411-22.

8. BRASIL. Instituto Brasileiro de Geografia e Estatística (IBGE). Censo 2010. Disponível em: http://www.ibge.gov.br/estadosat/perfil.php?sigla=df. Acesso em: 07 de out. 2019.

9. BRASIL. Instituto Brasileiro de Geografia e Estatística (IBGE). Síntese de Indicadores Sociais: uma análise das condições de vida da população brasileira. Disponível em: https://biblioteca.ibge.gov.br/visualizacao/livros/liv42820.pdf Acesso em: 07 de out. 2019.

10. BRASIL. Instituto Brasileiro de Geografia e Estatística (IBGE). Pesquisa Mensal de Emprego: algumas características da inserção das mulheres no mercado de trabalho - Recife, Salvador, Belo Horizonte, Rio de Janeiro, São Paulo e Porto Alegre, 2003-2008. Disponível em: https://ww2.ibge.gov.br/home/estatistica/indicadores/trabalhoerendimento/pme_mulher/Suplemento_ Mulher_2008.pdf. Acesso em: 07 de out. 2019.

11. BRASIL. Instituto Brasileiro de Geografia e Estatística (IBGE). Pesquisa mensal de emprego: mulher no mercado de trabalho - perguntas e respostas. Disponível em: https://ww2.ibge.gov.br/home/estatistica/indicadores/trabalhoerendimento/pme nova/Mulher_Merca do_Trabalho_Perg_Resp_2012.pdf. Acesso em: 07 de out. 2019.

12. Proni M. Teorias do desemprego. Brasília: TD, Ed. 256, 2015.

13. BRASIL. Ministério da Educação. Pronatec. Disponível em: < http://portal.mec.gov.br/pronatec $>$. Acesso em: 07 de out. 2019.

14. BRASIL. Ministério da Saúde. Secretaria de Atenção à Saúde. Programa dos Agentes Comunitários de Saúde. Brasília: Ministério da Saúde; 2001.

15. BRASIL. Ministério da Saúde. Política Nacional de Humanização - PNH. Brasília: Ministério da Saúde; 2013.

16. BRASIL. Casa Civil. Lei no 10.507, de 10 de julho de 2002. Cria a profissão de Agente Comunitário de Saúde e dá outras providências. Diário Oficial da União. Disponível em: http://www.planalto.gov.br/ccivil_03/LEIS/2002/L10507.htm. Acesso em: 07 de out. 2019.

17. Fraga OS. Agente comunitário de saúde: elo entre a comunidade e a equipe de ESF? Trabalho de Conclusão do Curso (Especialização em Saúde Coletiva). Faculdade de Medicina Universidade Federal de Minas Gerais, Minas Gerais, 2011.

18. Maciazeki-Gomes RC, Souza CD, Baggio L, Wachs F. O trabalho do Agente Comunitário de Saúde: possibilidades e desafios. Ciência \& Saúde Coletiva 2016; 21(5): 1637-1645.

19. Vianna IOA. Planejamento participativo na escola: um desafio ao educador. São Paulo: EPU; 1986.

20. Pattuzzo YG, Gonçalves ES. As múltiplas linguagens na Educação Infantil. Revista Científica Multidisciplinar Núcleo do Conhecimento 2019; 1(4): 53- 7.

21. BRASIL. Ministério do Trabalho. Projeto Escola do Trabalhador. Disponível em: 
http://escola.trabalho.gov.br/. Acesso em: 07 de out. 2019.

22. Martins CP, Luzio CA. Política Humaniza SUS: ancorar um navio no espaço. Interface (Botucatu) 2017; 21(60): 13-22.

23. BRASIL. Ministério da Saúde. Secretaria de Atenção à Saúde. Departamento de Atenção Básica. Guia prático do Agente Comunitário de Saúde. Brasília: Ministério da Saúde; 2009.

24. BRASIL. Ministério da Saúde. Manual de planejamento no SUS. Fundação Oswaldo Cruz. Brasília; 2016. 138 p.

25. Ferreira J, Celuppi IC, Baseggio L, Geremia DS, Madureira VSF et al. Planejamento regional dos serviços de saúde: o que dizem os gestores? Saúde e Sociedade 2018; 27(1): 69-79.

26. Santos AB, Silva GG, Pereira MER, Brito RS. Saúde Mental, Humanização e Direitos Humanos. Cadernos Brasileiros de Saúde Mental 2018; 10(25): 01-19. 